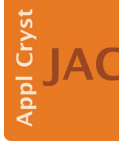

JOURNAL OF APPLIED CRYSTALLOGRAPHY

ISSN 1600-5767

Keywords: book reviews.

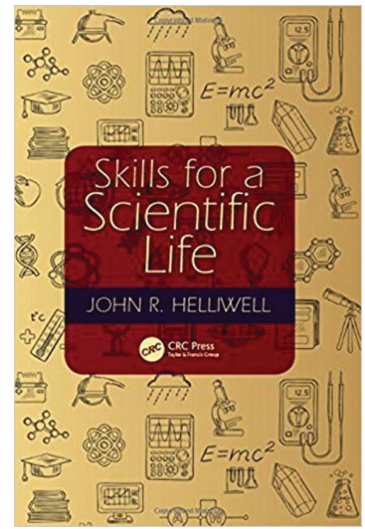

(C) 2017 International Union of Crystallography

\section{Skills for a Scientific Life. By John R. Helliwell. CRC Press, 2016. Pp. 197. Price GBP 25.59 (hardcover). ISBN 978-1-4987-6875-7.}

\author{
Elena V. Boldyreva*
}

Institute of Solid State Chemistry and Mechanochemistry, Siberian Branch of Russian Academy of Sciences, ulica Kutateladze 18, Novosibirsk, 630128, Russian Federation. *Correspondence e-mail: eboldyreva@yahoo.com

This is a rather unique book. I am sure that it will be very well received and in very high demand, especially among the younger generation. It has now been a few years since the General Interest Group of Young Crystallographers of the European Crystallographic Association (GIG2) initiated a series of microsymposia dubbed 'How to?'. Young people were interested to know how to lead successful research careers, both in their research and in related activities. The author of this book, Professor John R. Helliwell, was one of the first lecturers to be invited to speak at these microsymposia. This is fitting as he has much to teach in this respect. He has led a successful research career and trained successful students. He has worked as an academic in both physics and chemistry departments, and has additionally taught biochemists and molecular biologists as a guest lecturer. He holds degrees in both physics and molecular biophysics, and has held a faculty position as a professor of chemistry. Further, he has worked in the scientific 'civil service', having spent time as a head of department (overseeing a staff composed of 240 people) and acting as a senior mentor to new academics. The latter presented him with a wide range of general managerial training that complemented his extensive academic training. In addition to his university-based roles, John Helliwell has acted as a science research editor, including up to the level of editor-in-chief. John Helliwell has served the global crystallographic community through his numerous efforts to ensure speedy and effective growth at as many synchrotrons and neutron facilities as possible, and acted as the first Chair of the IUCr's Commission on Synchrotron Radiation. He was President of the European Crystallographic Association (2006-2009) and has served as Editor-inChief of the IUCr journals (1996-2005). In 2015 John Helliwell was awarded the 8th Max Perutz Prize from the European Crystallographic Association. This long list of achievements and contributions remains far from complete.

The topics of the book are underpinned by this immensely detailed and wide-ranging experience. The author has served (and continues to serve) as a role model for many young researchers, and sharing his experience with them is undoubtedly invaluable. The book is also of interest to the more senior generation: it suggests how to think of the general principles, values and skills for everyday activities and for lifelong strategy.

While the book is not very thick, its 197 pages are ripe with information. The book includes eight sections: How do you know you are suited to be a scientist, Skills for a better researcher, Being a good science research citizen, Skills for being an educator, Skills for realizing wider impacts, Leadership posts, Ethics, global development, policy and the organisation of science, and Appendices. These eight sections are, in turn, subdivided into 34 chapters and 11 appendices. All chapters and appendices start with 'How to' and contain concise recipes on all foreseeable situations. These subsections include how to undertake postdoctoral research; to recognize a good idea; to make significant discoveries; to write a successful grant proposal; to asses research risks; to set up, lead and care for a research team; to publish one's results; to communicate results; to manage time; to use a SWOT (strengths, weaknesses, opportunities, threats) analysis to good effect; to use social media; to avoid the travails of a research manager and the pitfall of ending up not doing science; to coexist with competitors; to deal with criticism; to effect collaborations; to hold a vision including avoiding politics and carrying on regardless of managerialism; to referee grant proposals; to referee science articles; to write a balanced book review; to be a science research editor; to chair meetings; to teach undergraduates and to supervise $\mathrm{PhD}$ postgraduate students; to be a good mentor; to reach out to wider audiences and 
explain your research; to handle inventions, patents and services to industry; to help improve gender equality; to know if you really want to be head of department; to lead your learned society if you are elected as its president; to lead your research community as an instrument scientist; to retain your own peace of mind (ethical aspects); to make your role a global one; to make your input into science policy; to deploy some very basic statistics when necessary in wider roles as a scientist; to write as clearly and concisely as possible; to keep to budget; to observe; to deal with bullying; to take decisions; to be a project sponsor; to write a reference; to delegate; to prepare to be a science expert witness; to explain the scientific method to the public and schoolchildren. This is a concise handbook that can serve as a guide throughout a scientific career.

References to each chapter and each appendix are complemented by a general bibliography. To the latter I personally would add one of my favorites: Hans Selye, From Dream to Discovery. On being a Scientist (Arno Press, New York, 1977, ISBN-0-405-06616-3). This is a book that I read when I was starting my scientific career and that has shaped it to a large extent. I hope that the new generation of researchers - the readers of the recent book by John Helliwell - will enjoy it, and that this book will shape their careers. I would recommend all young researchers to have a copy of this book on their desk. 